\title{
Human Globozoospermia-Related Gene Spata16 Is Required for Sperm Formation Revealed by CRISPR/Cas9-Mediated Mouse Models
}

\author{
Yoshitaka Fujihara ${ }^{1,2}$, Asami Oji 1,2,3, Tamara Larasati ${ }^{1,4}$, Kanako Kojima-Kita ${ }^{1,5}$ and \\ Masahito Ikawa $1,2,4,5,6, *$ (iD \\ 1 Research Institute for Microbial Diseases, Osaka University, Suita, Osaka 565-0871, Japan; \\ fujihara@biken.osaka-u.ac.jp (Y.F.); oji-a@cdb.riken.jp (A.O.); tamara@biken.osaka-u.ac.jp (T.L.); \\ kojima0208@patho.med.osaka-u.ac.jp (K.K.-K.) \\ 2 Graduate School of Pharmaceutical Sciences, Osaka University, Suita, Osaka 565-0871, Japan \\ 3 RIKEN Center for Developmental Biology, Kobe, Hyogo 650-0047, Japan \\ 4 School of Pharmaceutical Sciences, Osaka University, Suita, Osaka 565-0871, Japan \\ 5 Graduate School of Medicine, Osaka University, Suita, Osaka 565-0871, Japan \\ 6 The Institute of Medical Science, The University of Tokyo, Minato-ku, Tokyo 108-8639, Japan \\ * Correspondence: ikawa@biken.osaka-u.ac.jp; Tel.: +81-668-798-375
}

Received: 26 September 2017; Accepted: 19 October 2017; Published: 21 October 2017

\begin{abstract}
A recent genetic analysis of infertile globozoospermic patients identified causative mutations in three genes: a protein interacting with C kinase 1 (PICK1), dpy 19-like 2 (DPY19L2), and spermatogenesis associated 16 (SPATA16). Although mouse models have clarified the physiological functions of Pick1 and Dpy19l2 during spermatogenesis, Spata16 remains to be determined. Globozoospermic patients carried a homozygous point mutation in SPATA16 at 848G $\rightarrow$ A/R283Q. We generated CRISPR/Cas9-mediated mutant mice with the same amino acid substitution in the fourth exon of Spata16 to analyze the mutation site at R284Q, which corresponded with R283Q of mutated human SPATA16. We found that the point mutation in Spata16 was not essential for male fertility; however, deletion of the fourth exon of Spata16 resulted in infertile male mice due to spermiogenic arrest but not globozoospermia. This study demonstrates that Spata16 is indispensable for male fertility in mice, as well as in humans, as revealed by CRISPR/Cas9-mediated mouse models.
\end{abstract}

Keywords: genome editing; male infertility; mouse model; point mutation; spermatogenesis; testis

\section{Introduction}

Infertility is a major health concern around the world. One cause of male infertility is abnormal sperm formation due to genetic and/or epigenetic problems. Recent genetic studies of infertility patients identified causative mutations in three genes: a protein interacting with C kinase 1 (PICK1), dpy 19-like 2 (DPY19L2), and spermatogenesis associated 16 (SPATA16) [1-3]. These mutations were considered to be responsible for the infertility syndrome globozoospermia, caused by the malformation or loss of the sperm acrosome accompanied by an abnormal nuclear shape, as well as an abnormal arrangement of the sperm mitochondria. These abnormalities occur during spermatogenesis, especially during acrosome formation. The acrosome is a membrane-bound cap-like structure that covers the anterior portion of the sperm nucleus. In the testis, acrosome biogenesis has several steps: protein processing in the endoplasmic reticulum, vesicle trafficking from the Golgi apparatus, vesicle fusion, and the interaction of the acrosomal membrane with the nuclear membrane [4]. Globozoospermia is a rare infertility syndrome that shows severe abnormal sperm morphology. Although an intracytoplasmic sperm injection (ICSI) is a treatment option for infertile patients, globozoospermic spermatozoa show quite low rates of fertilization due to reduced oocyte activation 
ability [5]. The molecular mechanism of acrosome biogenesis and the mechanism that leads to globozoospermia remain to be determined.

PICK1 is a peripheral membrane protein that is ubiquitously expressed in mouse and human tissues [6,7]. PICK1 interacts with a number of membrane proteins and lipid molecules and regulates protein trafficking in the central nervous system [8]. Although Pick1 gene knockout (KO) mice were viable and showed no gross developmental defects [9], KO males were infertile with abnormal sperm heads reminiscent of globozoospermia [10]. PICK1 localizes to Golgi-derived proacrosomal vesicles and is involved in vesicle trafficking from the Golgi apparatus to the sperm acrosome in a mouse testis [10]. A homozygous missense mutation (G198A) in the thirteenth exon of the PICK1 gene was identified from globozoospermic patients in China [2]. This autosomal recessive genetic mutation in PICK1 was responsible for globozoospermia in humans.

DPY19L2 is a testis-specific transmembrane protein [11] localized to the inner nuclear membrane of mouse spermatids [12]. Globozoospermic patients were found to carry a $200 \mathrm{~kb}$ homozygous deletion encompassing the entire DPY19L2 locus [11,13]. A large cohort analysis of globozoospermic patients identified novel mutations and deletions of the DPY19L2 locus [1,14-17]. Moreover, the Dpy 1912 gene in KO mice also reproduced the infertile phenotype of globozoospermia with acrosomeless round-headed spermatozoa [12]. Therefore, DPY19L2 was found to be a major causative gene of globozoospermia in humans.

SPATA16 (previously named NYD-SP12) is highly expressed in human testes and contains a conserved tetratricopeptide repeat (TPR) domain which is known to mediate protein-protein interactions [18]. SPATA16 is localized to the Golgi apparatus and to the proacrosomal vesicles, which fuse to form the acrosome during spermiogenesis [19]. A homozygous mutation ( $848 \mathrm{G} \rightarrow \mathrm{A}$, $\mathrm{R} 283 \mathrm{Q}$ ) in the fourth exon of SPATA16 was identified in three affected brothers from an Ashkenazi Jewish family. The fourth exon of SPATA16 encodes the C-terminus of the TPR domain; the authors reported that the $848 \mathrm{G} \rightarrow \mathrm{A}$ mutation causes the disruption of the TPR domain due to fourth exon skipping [3]. However, this mutation was not found in 29 other patients with globozoospermia in Europe and North Africa [3]. These results may suggest that SPATA16 is not the main cause of globozoospermia in humans [4].

In gene KO mouse studies, various genes (Atg7 [20], Csnk2a2 [21], Dpy19l2 [12], Gba2 [22], Golga2 [23], Gopc [24], Hrb [25], Hsp90b1 [26], Mfsd14a [27], Pick1 [10], Sirt1 [28], Slc9a8 [29], Smap2 [30], Spaca1 [31], Tmf1 [32], Vps54 [33], Zpbp1 [34]) were found to be associated with globozoospermia [4]. Although almost all genes (14 out of 17 genes) were ubiquitously expressed, these genes were unexpectedly responsible for male fertility. Only three genes, Dpy19l2, Spaca1, and Zpbp1, were testis-specific in mice and humans. However, there are no reports of causative mutations of ZPBP1 and SPACA1 in infertile patients [4,35]. Although genetic studies of human SPATA16 have been reported, the physiological role of mouse Spata16 has not been determined.

In this study, we generated Spata16 mutant mice: a targeted point mutation $(851 \mathrm{G} \rightarrow \mathrm{A}, \mathrm{R} 284 \mathrm{Q})$ and a 781-bp deletion by CRISPR/Cas9. The targeted point mutation $(851 \mathrm{G} \rightarrow \mathrm{A}, \mathrm{R} 284 \mathrm{Q})$ was designed at the corresponding site ( $848 \mathrm{G} \rightarrow \mathrm{A}, \mathrm{R} 283 \mathrm{Q}$ ) of infertile patients with globozoospermia as previously reported [3]. The 781-bp deletion of the Spata16 locus caused the mis-translation of the fourth exon that encodes the C-terminus of the TPR domain.

\section{Results}

\subsection{Testis-Specific Expression and Protein Sequence Alignment of Mouse SPATA16}

The expression of mouse Spata16 in various organs was examined by RT-PCR analysis. Spata16 was exclusively expressed in mouse testes (Figure 1A), as previously reported in humans [18]. Next, the onset of Spata16 expression was examined by RT-PCR and compared with that of globozoospermia-related genes: Dpy19l2 [12], Pick1 [10], and Spaca1 [31]. Although Pick1 was first detected in a one-week-old testis, Spata16 and Dpy19l2 were expressed in a two-week-old testis 
(Figure 1B). Spaca1 was detected in a three-week-old testis during the acrosome formation stage [31]. These data showed that mouse Spata16 is a testis-specific gene and begins expression prior to acrosomal biogenesis. Figure $1 \mathrm{C}$ shows the sequence similarity of the SPATA16 protein among species. SPATA16 is highly conserved in mammals, from mice to humans. More than $90 \%$ of the TPR domain is identical between mice and humans [3]. The point mutation $(848 \mathrm{G} \rightarrow \mathrm{A})$ causing a single amino acid substitution (R283Q) at the C-terminal end of the TPR domain was found in globozoospermic patients [3]. This amino acid, R284, is also conserved in mice (asterisk in Figure 1C).

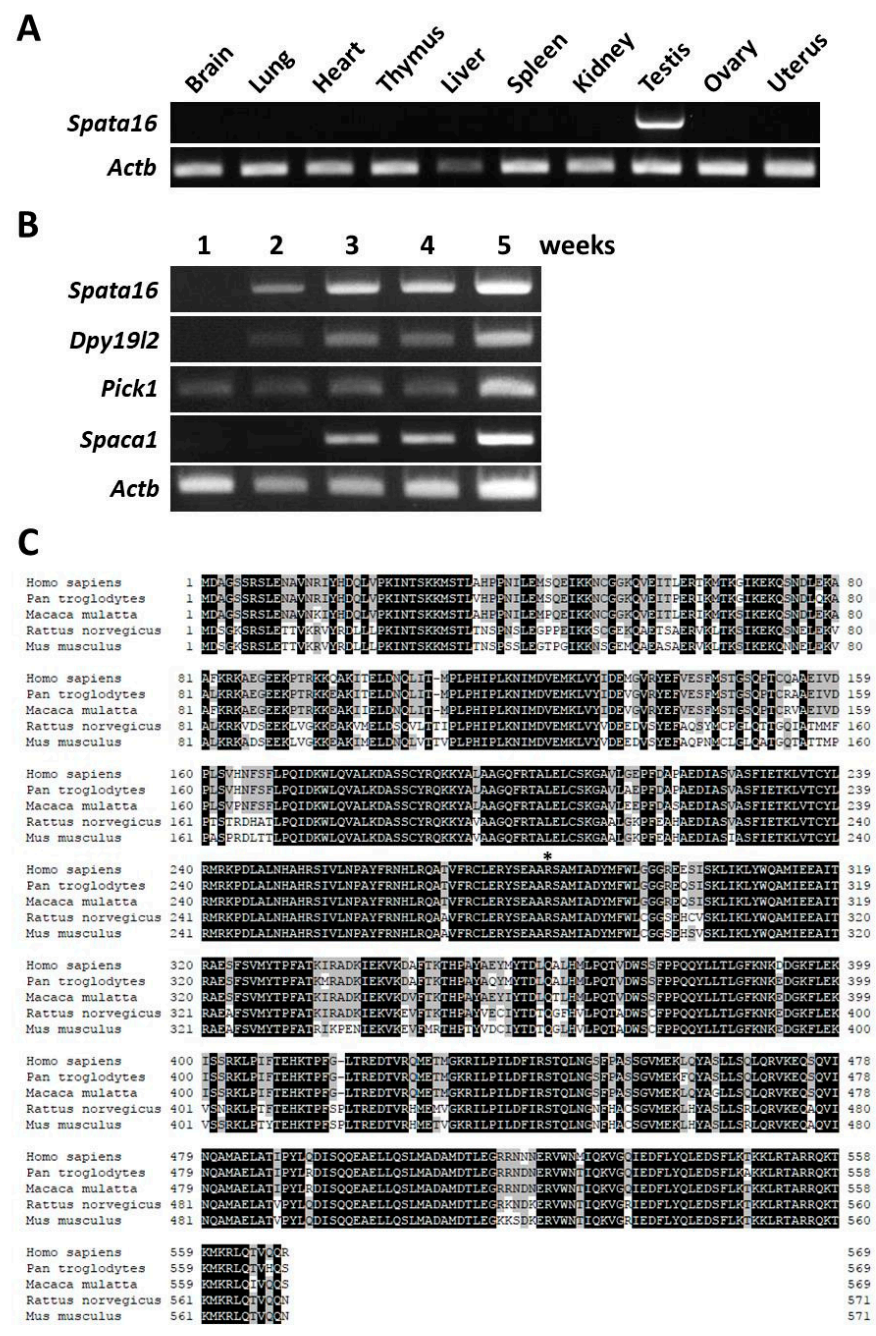

Figure 1. Characterization of mouse Spata16. (A) Testis-specific expression of Spata16 by multi-tissue RT-PCR analysis. The expression of mouse Spata16 was examined by RT-PCR using RNA isolated from various organs. Spata16 was only detected in the testis. The Actb gene was used as an expression control; (B) RT-PCR analysis of Spata16 and other globozoospermia-related genes in the mouse testis. Spata16 and Dpy 1912 were first expressed in a two-week-old testis. The onset of Spata16 expression occurred prior to that of Spacal encoding a sperm acrosomal protein; (C) Sequence similarity of SPATA16 protein in mammals. Black indicates a match in all species. Gray indicates a match among at least three species. The 283rd arginine residue of human SPATA16 as previously reported [3] is indicated by an asterisk. $79 \%$ of the SPATA16 amino acid sequence is identical between humans and mice.

\subsection{Targeted Point Mutation and Deletion of Spata16 by CRISPR/Cas9}

To study the human point mutation and function of the mouse Spata16 gene in vivo, we produced a Spata16 point mutant $(851 \mathrm{G} \rightarrow \mathrm{A}, \mathrm{R} 284 \mathrm{Q})$ and deleted 781 bp from mice by CRISPR/Cas9 using embryonic 
stem (ES) cells (Figures 2A and 3A). The Spata16 point mutant (851G $\rightarrow$ A, R284Q) and the 781-bp deletion obtained from chimeric males were confirmed by PCR (Figures 2B and 3B) and direct sequencing (Figures $2 \mathrm{C}$ and $3 \mathrm{C}$ ) analyses. An RT-PCR analysis of the Spata16 point mutant testis showed a single band at 498 bp identical to that of a wild-type testis (Figure 2D). These data indicated that the point mutation in the fourth exon caused no splicing abnormality. The mouse line with the 781-bp deletion removed $88 \mathrm{bp}$ out of $90 \mathrm{bp}$ of the fourth exon of Spata16 (Figure 3C). This mutation resulted in the mis-translation of the fourth exon encoding the C-terminus of the TPR domain, which was confirmed by the RT-PCR of a Spata16 ${ }^{-781 /-781}$ testis (Figure 3D,E). These results confirmed that we generated a Spata16 point mutant $\left(851 \mathrm{G} \rightarrow \mathrm{A}, \mathrm{R} 284 \mathrm{Q}\right.$, Spata16 $\mathrm{pm}^{\mathrm{m}}$ ) and a 781-bp deletion (fourth exon skipped).

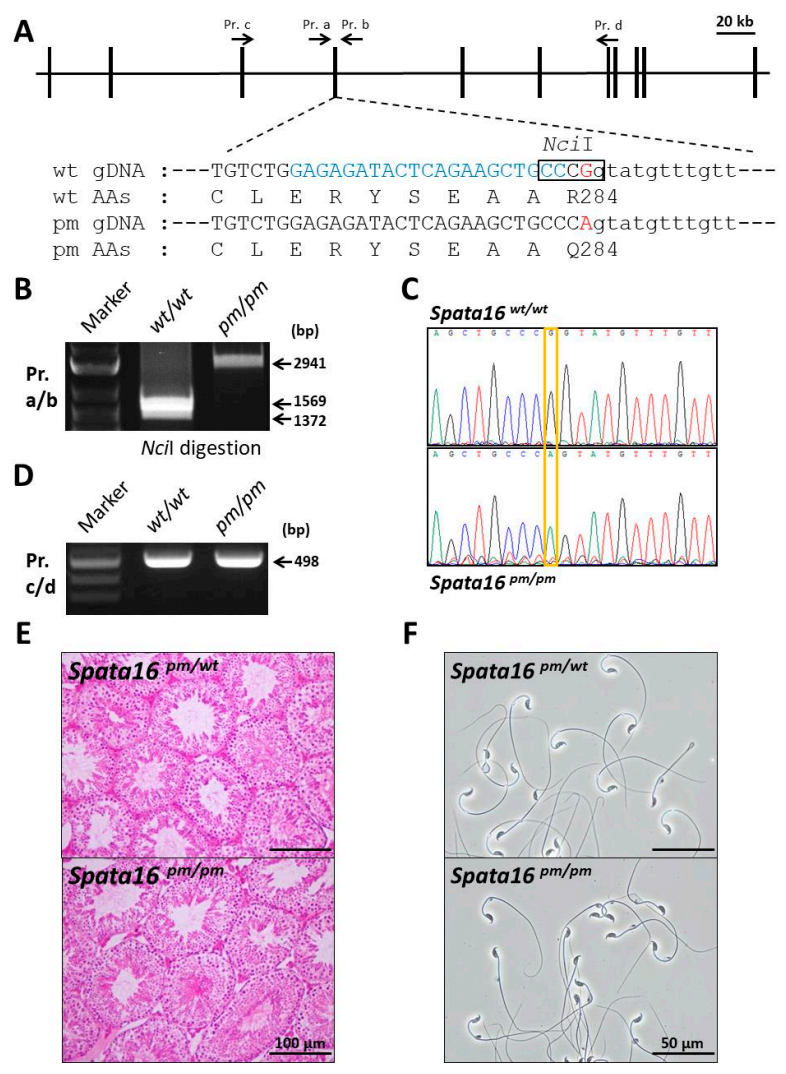

Figure 2. Targeted point mutation ( $851 \mathrm{G} \rightarrow \mathrm{A}, \mathrm{R} 284 \mathrm{Q})$ of Spata16 by CRISPR/Cas9. (A) Targeting scheme of the point mutation $(851 \mathrm{G} \rightarrow \mathrm{A}, \mathrm{R} 284 \mathrm{Q})$ in the fourth exon of mouse Spata16. Spata16 consists of eleven exons. The point mutation was introduced into mouse ES cells using the HDR donor plasmid with $0.5 \mathrm{~kb}$ homology arms. Blue indicates the sgRNA sequence. Red indicates a $G \rightarrow$ A mutation at the last nucleotide (851st coding exon) of the fourth exon of Spata16. Capital and small letters indicate nucleotides of exons and introns, respectively; (B) The genotyping of point-mutant mice by Ncil digestion. The NciI recognition site (5'-CCCGG-3') was disrupted due to the $\mathrm{G} \rightarrow$ A mutation of the fourth exon. In wild-type mice, two bands (1372 bp and 1569 bp) were detected after NciI digestion; (C) Direct sequencing of PCR products in Spata16 $\mathrm{Pm} / \mathrm{pm}$ mice. The $\mathrm{G} \rightarrow \mathrm{A}$ mutation at the last nucleotide (851st coding exon) of the fourth exon is indicated by the orange square; (D) RT-PCR analysis of a testis in Spata16 $\mathrm{pm} / \mathrm{pm}$ mice. The 498-bp band was amplified from wild-type and Spata $16^{\mathrm{pm} / \mathrm{pm}}$ mice. A point mutation causing an inappropriate splicing was not found in Spata16 $\mathrm{pm} / \mathrm{pm}$ mouse testes; (E) Representative testicular histology sections stained with hematoxylin and eosin. Spermatogenesis in Spata16 $\mathrm{pm} / \mathrm{pm}$ mice looked normal compared with that in Spata16 $\mathrm{pm} /$ wt mice. Scale bars: $100 \mu \mathrm{m}$; (F) Cauda epididymal spermatozoa from Spata $16^{\mathrm{pm} / \mathrm{wt}}$ and Spata16 $\mathrm{pm} / \mathrm{pm}$ mice. There were no sperm morphology differences between Spata16 $\mathrm{pm} / \mathrm{wt}$ and Spata16 $\mathrm{pm} / \mathrm{pm}$ mice. Spata16 $\mathrm{pm} / \mathrm{pm}$ males were fertile. Scale bars: $50 \mu \mathrm{m}$. 

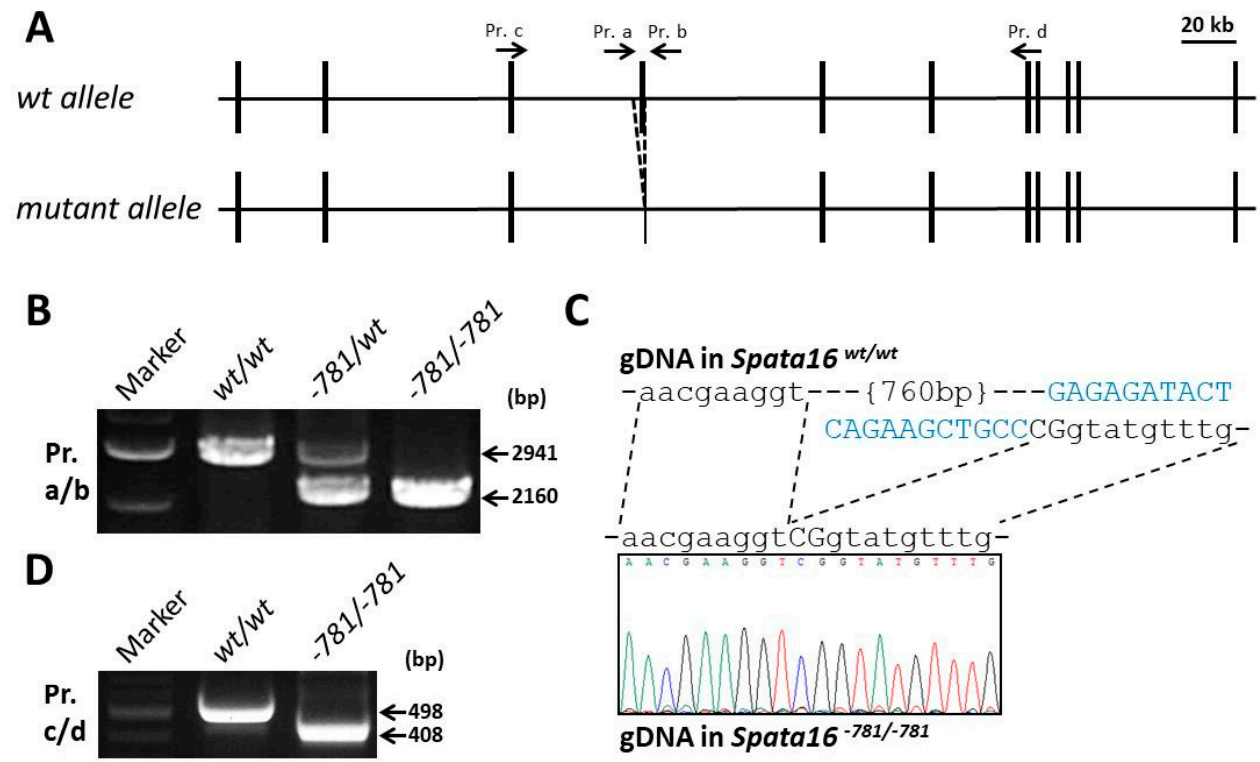

E

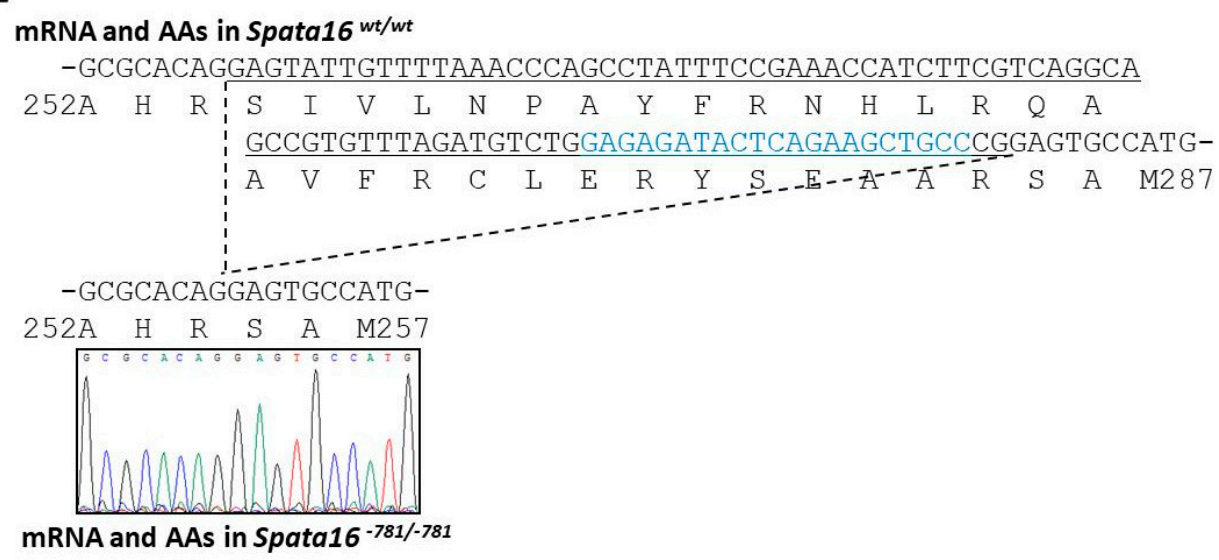

Figure 3. 781-bp deletion of Spata16 by CRISPR/Cas9. (A) Targeting scheme of the 781-bp deletion in the mouse Spata16 locus; (B) The genotyping of Spata16 $6^{-781 /-781}$ mice by PCR analysis. Both the wild-type allele band at $2941 \mathrm{bp}$ and the deleted allele band at $2160 \mathrm{bp}$ were amplified by PCR; (C) Direct sequencing of the 781-bp deletion around the Spata16 fourth exon. Capital and small letters indicate nucleotides of the exon and intron, respectively. Blue indicates the sgRNA sequence; (D) RT-PCR analysis of a testis in Spata16-781/-781 mice. The 498-bp and 408-bp bands were amplified from wild-type and Spata16 ${ }^{-781 /-781}$ mice, respectively; (E) Direct sequencing of Spata16 mRNAs in wild-type and Spata16 ${ }^{-781 /-781}$ mice. The 781-bp deletion around the fourth exon in Spata1 $6^{-781 /-781}$ mice caused the mis-translation of the remaining $2 \mathrm{bp}\left(5^{\prime}-\mathrm{CG}-3^{\prime}\right)$ of the mutant fourth exon. Blue indicates the sequence of the sgRNA.

\subsection{Fertilizing Ability of Spata16 Mutant Male Mice}

No overt developmental abnormalities were observed in the Spata16 mutant mouse lines produced. To examine male fertility, adult Spata16 mutant males were mated with wild-type or mutant females for several months. Whereas the Spata16 $\mathrm{pm} / \mathrm{wt}, \operatorname{Spata16} \mathrm{pm} / \mathrm{pm}$, and Spata16 ${ }^{-781 / \mathrm{wt}}$ males were fertile, the Spata16 ${ }^{-781 /-781}$ males were completely sterile despite showing normal mating behavior with successful ejaculation and vaginal plug formation. The mean litter size in Spata16 $\mathrm{pm} / \mathrm{wt}$ males was $9.7 \pm 0.6(n=3), 7.7 \pm 2.5(n=3)$ in Spata16 $\mathrm{pm}^{\mathrm{pm}}$ males, and $9.8 \pm 3.3(n=4)$ in Spata16 $6^{-781 / \mathrm{wt}}$ males. The R284Q point-mutant SPATA16 protein caused no deleterious effects on testicular histology (Figure 2E). Spermatozoa produced by Spata16 $\mathrm{pm} / \mathrm{pm}$ mice were motile and morphologically normal 
under phase-contrast microscopy (Figure 2F). Spata16 $\mathrm{pm}^{\mathrm{pm}}$ and Spata16 ${ }^{-781 /-781}$ females were fertile as expected, as Spata16 is a testis-specific gene (Figure 1A). Although the R284Q point mutation in SPATA16 was not critical for spermatogenesis, SPATA16 was essential for male fertility in mice.

\subsection{Spermiogenic Arrest in Spata16 ${ }^{-781 /-781}$ Mice}

To analyze the infertility of Spata16 ${ }^{-781 /-781}$ males, we observed the testis and epididymis in Spata16 $6^{-781 /-781}$ mice. Although the epididymis in Spata16 $6^{-781 /-781}$ mice was morphologically normal, the testicular size and weight of Spata16 $6^{-781 /-781}$ mice were significantly decreased compared with those of wild-type mice $\left(104.6 \pm 3.2\right.$ and $65.9 \pm 4.4 \mathrm{mg}$ in the wild-type and Spata16 ${ }^{-781 /-781}$ testis, respectively; $p<0.005$ ) (Figure $4 \mathrm{~A}, \mathrm{~B}$ ). To examine the cause of the reduced testicular weight in Spata16 ${ }^{-781 /-781}$ mice, morphological analysis was performed for testicular sections stained by PAS (Figure 4C) and immunofluorescences (Figure S1). Abnormal spermatogenesis was apparent in Spata16 $6^{-781 /-781}$ mice (the rate of normal spermatogenesis: 103/103 tubules in the wild-type testis and 30/86 tubules in the Spata16 $6^{-781 /-781}$ testis). Observation of the green acrosome derived from the Acr-Egfp transgene and the acrosomal membrane protein SPACA1 showed spermiogenic arrest in Spata16 ${ }^{-781 /-781}$ mice (Figure S1). Spermiogenic arrest observed in Spata16 ${ }^{-781 /-781}$ mice likely leads to reduced testicular weight in those mice. Next, to examine the morphology of epididymal spermatozoa in Spata16 $6^{-781 /-781}$ mice, we observed epididymal sections stained by hematoxylin and eosin (Figure 4D,E). Although spermatozoa were observed in all tubules of the caput and cauda epididymides in wild-type mice, only a few spermatozoa were detected in those of the caput and cauda epididymides in Spata16 $6^{-781 /-781}$ mice. The cells extracted from cauda epididymis in Spata16 ${ }^{-781 /-781}$ mice were observed and classified using morphological and immunofluorescence analyses. Almost all extracted cells were arrested at the round spermatid stage in Spata16 $6^{-781 /-781}$ mice (Figure $4 \mathrm{~F}$ and Figure S2). Seven percent of extracted cells (30/438 cells) were spermatozoa but with abnormal heads and tails, while all cells (334/334 cells) were normal spermatozoa in wild-type mice (Figure 4G). To confirm that the cells were extracted from the cauda epididymis, we performed an immunoblot analysis of three proteins as markers. BASIGIN has been known to change its molecular weight from the testicular size ( $35 \mathrm{kDa})$ to the epididymal size $(25 \mathrm{kDa})$ [36]. SPACA1 is as a marker for acrosome biogenesis [31], and SLC2A3 is as a marker for the sperm tail in the epididymis. The cells extracted from the cauda epididymis in Spata16 ${ }^{-781 /-781}$ mice showed aberrant retention of testicular BASIGIN $(35 \mathrm{kDa})$ and the reduction of SPACA1 and SLC2A3 (Figure 4H). Although other KO mice with a globozoospermia-like phenotype showed a significant reduction of testicular SPACA1 [31], SPACA1 remained in the Spata16 $6^{-781 /-781}$ mouse testis (Figure $4 \mathrm{H}$ ). These results indicated that the testicular remnants, including round spermatids, abnormally migrated from the testis to the cauda epididymis in Spata16 ${ }^{-781 /-781}$ mice. The Spata16 gene in mice, especially the fourth exon encoding the TPR domain, is essential for sperm formation, as revealed by Spata16 mutant mice. 
A

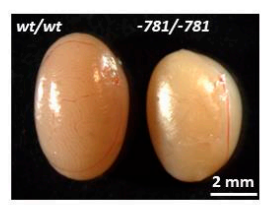

D

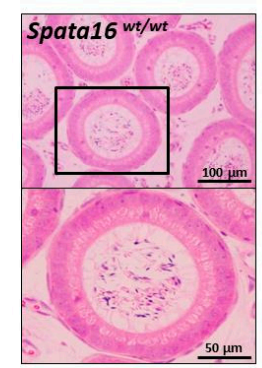

F

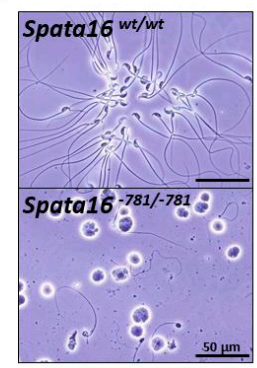

B

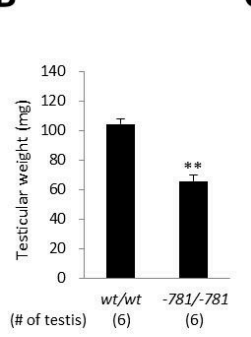

E
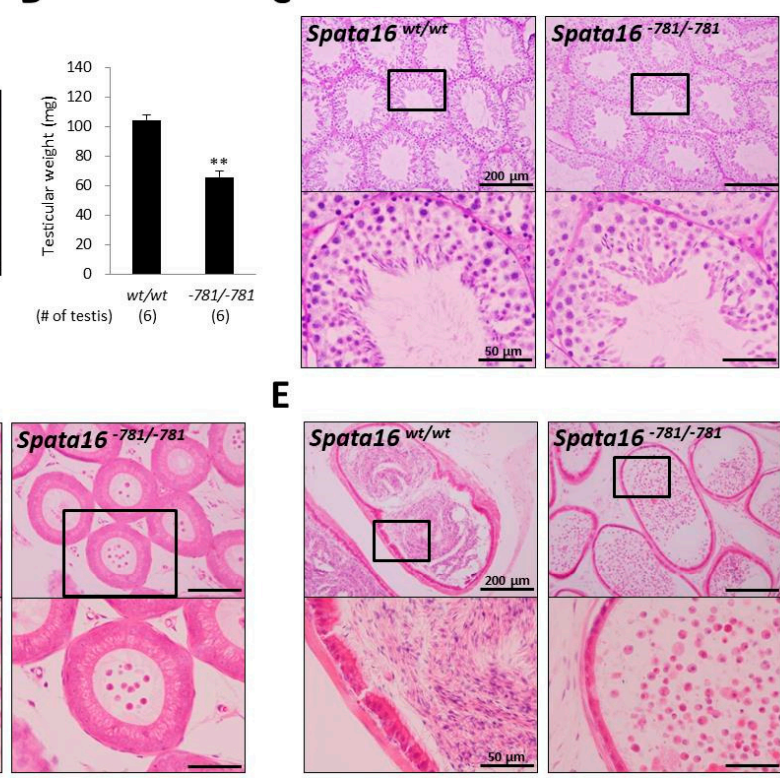

G
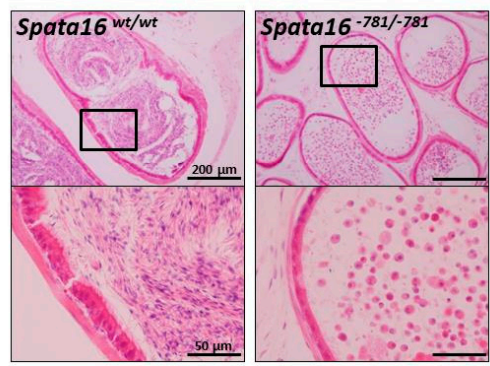

H

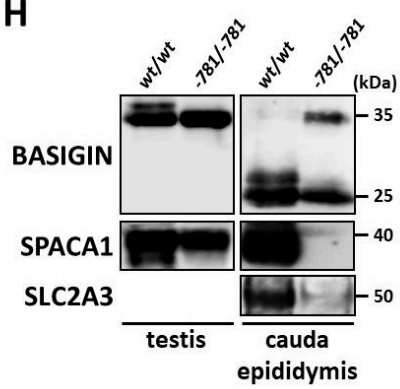

Figure 4. Spermiogenic arrest in Spata16 $6^{-781 /-781}$ mice. (A) Testes in wild-type and Spata16 $781 /-781$ mice. Scale bar: $2 \mathrm{~mm}$; (B) Testicular weights in wild-type and Spata16 $6^{-781 /-781}$ mice. Testicular weights in Spata16 $6^{-781 /-781}$ mice were significantly reduced compared with those in wild-type mice. ${ }^{* *} p<0.005$; (C) PAS staining of testicular sections. Lower figures are magnified images of the boxes indicated in the upper figures. Scale bars: upper; $200 \mu \mathrm{m}$ and lower; $50 \mu \mathrm{m}$; (D) HE stained sections of caput epididymis. Lower figures are magnified images of the boxes indicated in the upper figures. Scale bars: upper; $100 \mu \mathrm{m}$ and lower; $50 \mu \mathrm{m}$; (E) HE stained sections of cauda epididymis. Lower figures are magnified images of the boxes indicated in the upper figures. Scale bars: upper; $200 \mu \mathrm{m}$ and lower; $50 \mu \mathrm{m}$; (F) Observation of cells extracted from cauda epididymis. Scale bars: $50 \mu \mathrm{m}$; (G) Quantitative morphometric analysis of round spermatid and sperm from cauda epididymis. Dashed line indicates a significant reduction in sperm-like cells extracted from the cauda epididymis in Spata16 ${ }^{-781 /-781}$ mice. ${ }^{* *} p<0.005 ;(\mathbf{H})$ Immunoblot analysis of cell lysates collected from a testis and cauda epididymis. Sperm acrosomal protein SPACA1 remained in the Spata16 $6^{-781 /-781}$ mouse testis. In cauda epididymal lysates from Spata16 $6^{-781 /-781}$ mice, the aberrant retention of testicular BASIGIN was detected and sperm tail-specific protein SLC2A3 and SPACA1 were decreased. Spata16 $6^{-781 /-781}$ male mice were sterile because of a spermiogenic arrest. $20 \mu \mathrm{g}$ of cell lysates were loaded in each lane.

\section{Discussion}

Globozoospermia is a cause of male infertility characterized by round-headed spermatozoa with an absent acrosome, aberrant nuclear membrane morphology, and sperm midpiece defects [5]. Recently, causative mutations and deletions in three genes, DPY19L2, PICK1, and SPATA16, have been identified from globozoospermic patients $[2,3,11,17]$. KO mouse experiments also identified seventeen genes responsible for globozoospermia-like phenotypes [4]. Although Dpy19l2 and Pick1 have been reported in $\mathrm{KO}$ mice, the physiological role of Spata16 has not been determined. 
In this study, we generated CRISPR/Cas9-mediated Spata16 mutant mouse lines, an $851 \mathrm{G} \rightarrow \mathrm{A} / \mathrm{R} 284 \mathrm{Q}$ point mutant and a 781-bp deletion. Although globozoospermic patients have a homozygous mutation $(848 \mathrm{G} \rightarrow \mathrm{A}, \mathrm{R} 283 \mathrm{Q})$ in the fourth exon of SPATA16 [3], Spata16 pm/pm $(851 \mathrm{G} \rightarrow \mathrm{A}$, $\mathrm{R} 284 \mathrm{Q}$ ) male mice were fertile. Dam et al.'s paper reported that the $848 \mathrm{G} \rightarrow$ A mutation disrupts the $5^{\prime}$ splicing site of the fourth intron analyzed by in vitro cell transfection experiments and therefore leads to inappropriate splicing of the fourth exon and disruption of the TPR domain of SPATA16. However, in Spata16 $\mathrm{pm}^{\mathrm{pm}}$ (851G $\rightarrow$ A, R284Q) mice, this mutation did not affect the splicing of the fourth intron (Figure 2D).

In contrast, the Spata16 ${ }^{-781 /-781}$ males were infertile due to spermiogenic arrest, despite 781-bp deletion causing an in-frame mutation of Spata16 by mis-translation of the fourth exon (Figures 3E and 4). These results suggested that Spata16's fourth exon encoding the C-terminus of the TPR domain is essential for sperm formation and male fertility in mice. In-frame mutations resulting from fourth exon skipping (30 AAs) may also occur in globozoospermic patients with a homozygous point mutation ( $848 \mathrm{G} \rightarrow \mathrm{A}, \mathrm{R} 283 \mathrm{Q}$ ). Further experiments may be required to examine SPATA16 mRNA expression in globozoospermic patients with a homozygous SPATA16 mutation.

We found differences in the phenotype of SPATA16 mutations between humans and mice. Although the mutation of human SPATA16 caused globozoospermia with round-headed spermatozoa, Spata16 $6^{-781 /-781}$ mice were infertile with spermiogenic arrest, with impaired differentiation of round spermatids into the mature spermatozoa (Figure 4C). In round spermatids, SPATA16 and PICK1 are both localized to the Golgi apparatus [8,19]. Pick1 KO mice have impaired acrosome formation caused by the abnormal trafficking of acrosomal vesicles from the Golgi to the acrosome [10]. However, Spata16 $6^{-781 /-781}$ mice had normal acrosome biogenesis as observed by the green acrosome encoding Acr-Egfp transgene and SPACA1 protein remaining in the Spata16 ${ }^{-781 /-781}$ testis (Figure $4 \mathrm{H}$ and Figure S1). Testicular SPACA1 is essential for acrosomal formation and is a downstream factor of the other globozoospermia-related proteins [31]. Because the amount of testicular SPACA1 only slightly reduced in Spata16 $6^{-781 /-781}$ mice, we can assume that mouse SPATA16 is not related to globozoospermia. Accordingly, mouse SPATA16 is required to progress through the sperm formation, differing from globozoospermic patients with a homozygous SPATA16 mutation. In humans and mice, frameshift mutations and the knockout of Spata16 will unveil the physiological functions of SPATA16. Moreover, proteins that bind with the SPATA16 TPR domain may imply a key role in spermatogenesis. Thus, to elucidate why patients with SPATA16 mutations show infertility causing globozoospermia, further study of other binding proteins is necessary.

\section{Materials and Methods}

\subsection{Animals}

All animal experiments were approved by the Animal Care and Use Committee of the Research Institute for Microbial Diseases, Osaka University (approval code: H25-02-0; approval date: 21 June 2013). Mice were maintained under a 12-h light/dark cycle. Wild-type mice were purchased from CLEA Japan (Tokyo, Japan) and Japan SLC (Shizuoka, Japan).

\subsection{RT-PCR}

Mouse cDNA was prepared from multiple adult tissues and from one- to five-week-old testes of ICR mice. To confirm the mutation in Spata16 $6^{-781 /-781}$ mice, RT-PCR was performed using RNA from a testis. The amplification conditions were $1 \mathrm{~min}$ at $94{ }^{\circ} \mathrm{C}$, followed by 30 cycles of $94{ }^{\circ} \mathrm{C}$ for $30 \mathrm{~s}, 65^{\circ} \mathrm{C}$ for $30 \mathrm{~s}$, and $72{ }^{\circ} \mathrm{C}$ for $30 \mathrm{~s}$, with a final seven-minute extension at $72{ }^{\circ} \mathrm{C}$. The primers used are listed in Table S1.

\subsection{Protein Sequence Alignment among Mammals}

Protein sequence alignment was performed as described previously [37]. 


\subsection{Construction of the HDR Donor Plasmid for Point Mutation in Spata16}

The Spata16 gene in mice consists of eleven exons and maps to chromosome 3. The reference plasmid was designed to introduce point mutation in the fourth exon of Spata16 and was constructed in the pBluescript II SK (+) vector. Homology arms, each $0.5 \mathrm{~kb}$ in length, were amplified by PCR using genomic DNA derived from C57BL/6 mice as a template. The primers used are listed in Table S1. The R284Q amino acid substitution of mouse SPATA16 corresponds with the same position $(848 \mathrm{G} \rightarrow \mathrm{A}, \mathrm{R} 283 \mathrm{Q})$ of globozoospermic patients [3]. This targeted point mutation prevented the genomic re-cleavage after homology-directed repair (HDR).

\subsection{Generation of Spata16 Mutant Mice with CRISPR/Cas9}

Spata16 mutant mice were produced by the transfection of pX330 plasmids (https:// www.addgene.org/42230/) with the HDR donor plasmid into ES cells, EGR-G01 [129S2 $\times$ C57BL/6N-Tg(CAG/Acr-Egfp)], as described previously [38,39]. A search for single guide RNAs (sgRNAs) and off-target sequences was performed using CRISPRdirect software (https:// crispr.dbcls. jp/) [40]. The sgRNA sequence used for transfection was: 5'-GAGAGATACTCAGAAGCTGCC-3'. Screening of ES cell clones was performed by direct sequencing following PCR. The primers used are listed in Table S1. Twenty four clones of transfected ES cells were selected and screened by NciI digestion following PCR. Eight clones contained a disruption at the NciI restriction site and were also confirmed by direct sequencing. Four out of eight clones introduced the targeted point mutation with other indels (insertion/deletion). Three correctly targeted clones were used to make chimeric mice by a microinjection. The mutant ES cell clones were injected into eight-cell stage ICR embryos, and chimeric blastocysts were transferred into the uterine horns of pseudopregnant ICR females the next day. To confirm germline transmission, chimeric males were mated with B6D2F1 females. Spata16 point mutant mice were genotyped by NciI restriction enzyme (New England Biolabs, Ipswich, MA, USA) digestion following PCR. The NciI recognition site (5'-CCCGG-3') was disrupted by the point mutation (G to A) at the last nucleotide of the fourth exon. Spata16 781-bp deleted mice were genotyped by a $2.9 \mathrm{~kb}$ band as the wild-type allele and a $2.2 \mathrm{~kb}$ band as the mutant allele.

The Spata16 mutant mouse lines, STOCK-Spata16 <em1(R284Q)Osb)> and STOCK-Spata16 $<\mathrm{em} 2 \mathrm{Osb}>$, were deposited to the RIKEN BioResource Center (http://mus.brc.riken.jp/en/) and the Center for Animal Resources and Development (CARD), Kumamoto University (http:/ / card. medic.kumamoto-u.ac.jp/card/english/).

\subsection{Male Fertility Test}

Sexually mature mutant male mice were caged with two-month-old B6D2F1 or mutant females for several months, and the number of pups in each cage was counted within a week of birth. Average litter sizes are presented as the number of total pups born divided by the number of litters for each genotype.

\subsection{Testis Weights, Testis Histology, and Sperm Morphology}

After breeding studies, males were sacrificed by cervical dislocation following anesthesia. Testes were weighed individually. Testes were fixed in $4 \%$ paraformaldehyde in PBS and were processed for paraffin embedding or frozen section. Five micron paraffin sections were stained with periodic acid-Schiff (PAS) and then counterstained with Mayer hematoxylin solution (Wako, Osaka, Japan). Ten micron frozen sections were stained with antibodies for immunostaining. Round spermatids and cauda epididymal spermatozoa were dispersed in PBS, observed under phase-contrast to assess morphology. 


\subsection{Antibodies}

The monoclonal antibodies used here were described previously: KS64-10 for SLC2A3 [41]. Polyclonal antibodies were purchased from Santa Cruz Biotechnology (sc-9757 for BASIGIN) and Acris Antibodies (BP5112 for SPACA1). Rabbit antisera against SPACA1 were described previously [31].

\subsection{Immunostaining}

Immunostaining was performed as described previously [42,43]. Briefly, all samples were mounted on glass slides and dried. After washing with PBS, slides were blocked with $10 \%$ New Born Calf Serum (NBCS)/PBS for $1 \mathrm{~h}$ and incubated with antibodies in $10 \%$ NBCS/PBS at $4{ }^{\circ} \mathrm{C}$ overnight. After washing with 10\% NBCS/PBS containing 0.05\% Tween-20, the slides were incubated with secondary antibodies in 10\% NBCS/PBS for $1 \mathrm{~h}$. After washing with PBS containing $0.05 \%$ Tween-20, the slides were observed under a fluorescence microscope (IX70, Olympus, Tokyo, Japan).

\subsection{Immunoblot}

Immunoblot analysis was performed as described previously [44]. Briefly, testicular germ cells were collected from the seminiferous tubules of testes. Sperm samples were collected from the cauda epididymis and vas deferens. These samples were homogenized in lysis buffer containing 1\% Triton X-100 and 1\% protease inhibitors (Nacalai Tesque, Kyoto, Japan), and then centrifuged with the supernatants, before being collected. Protein lysates were resolved by SDS/PAGE under reducing condition and transferred to PVDF membranes (Merck Millipore, Burlington, MA, USA). After blocking, blots were incubated with primary antibodies overnight at $4{ }^{\circ} \mathrm{C}$, and then incubated with secondary antibodies conjugated with horseradish-peroxidase. The detection was performed using an ECL plus western blotting detection kit (GE Healthcare, Little Chalfont, UK).

\subsection{Statistical Analysis}

Statistical analyses were performed using a Student's $t$-test inserted in Excel 2016 (Microsoft, Redmond, WA, USA) after the data were tested for the normality of distribution. Differences were considered significant at $\left.p<0.005{ }^{* *}\right)$.

\section{Conclusions}

We have generated a CRISPR/Cas9-mediated mouse model of an SPATA16 point mutation found in globozoospermic patients. Spata16 point mutant mice were fertile suggesting that this mutation $(851 G \rightarrow A, R 284 Q)$ is dispensable for sperm function in mice. This mutation was localized to the fourth exon of the SPATA16 gene in humans and mice. The replacement of the mouse fourth intron with that of the human SPATA16 fourth intron by CRISPR/Cas9 may provide the ideal model for the point mutation seen in human globozoospermia (Figure S3). Deletion of the fourth exon of mouse Spata16 caused male infertility with a spermiogenic arrest. Therefore, Spata16 itself is indispensable for spermiogenesis and male fertility in mice. Further investigations will be required to clarify the mechanism of SPATA16 during spermiogenesis and the differences in phenotype between humans and mice. These investigations have been aided by CRISPR/Cas9-mediated genome editing, which has emerged as a powerful and efficient method in the biomedical sciences and holds enormous promise for genetic research and therapy in human infertility.

Supplementary Materials: Supplementary materials can be found at www.mdpi.com/1422-0067/18/10/2208/s1.

Acknowledgments: This work was supported by the Ministry of Education, Culture, Sports, Science and Technology (MEXT)/Japan Society for the Promotion of Science (JSPS) KAKENHI Grants (JP15H05573 to Yoshitaka Fujihara, JP25112007 and JP17H01394 to Masahito Ikawa); Takeda Science Foundation Grants to Yoshitaka Fujihara and Masahito Ikawa; the Eunice Kennedy Shriver National Institute of Child Health and Human Development (R01HD088412 and P01HD087157); and The Bill and Melinda Gates Foundation (Grand Challenges Explorations grant OPP1160866). We thank Naoko Nagasawa and the Biotechnology Research and 
Development (nonprofit organization) for technical assistance, and Julio M. Castaneda and Ferheen Abbasi for critical reading of the manuscript.

Author Contributions: Yoshitaka Fujihara, Asami Oji, and Masahito Ikawa designed the research; Yoshitaka Fujihara, Asami Oji, Tamara Larasati, Kanako Kojima-Kita, and Masahito Ikawa performed the research; Yoshitaka Fujihara, Asami Oji, and Masahito Ikawa analyzed the data; and Yoshitaka Fujihara and Masahito Ikawa wrote the paper.

Conflicts of Interest: The authors declare no conflict of interest.

\section{References}

1. Elinati, E.; Kuentz, P.; Redin, C.; Jaber, S.; Vanden Meerschaut, F.; Makarian, J.; Koscinski, I.; Nasr-Esfahani, M.H.; Demirol, A.; Gurgan, T.; et al. Globozoospermia is mainly due to DPY19L2 deletion via non-allelic homologous recombination involving two recombination hotspots. Hum. Mol. Genet. 2012, 21, 3695-3702. [CrossRef] [PubMed]

2. Liu, G.; Shi, Q.W.; Lu, G.X. A newly discovered mutation in PICK1 in a human with globozoospermia. Asian J. Androl. 2010, 12, 556-560. [CrossRef] [PubMed]

3. Dam, A.H.; Koscinski, I.; Kremer, J.A.; Moutou, C.; Jaeger, A.S.; Oudakker, A.R.; Tournaye, H.; Charlet, N.; Lagier-Tourenne, C.; van Bokhoven, H.; et al. Homozygous mutation in SPATA16 is associated with male infertility in human globozoospermia. Am. J. Hum. Genet. 2007, 81, 813-820. [CrossRef] [PubMed]

4. Coutton, C.; Escoffier, J.; Martinez, G.; Arnoult, C.; Ray, P.F. Teratozoospermia: Spotlight on the main genetic actors in the human. Hum. Reprod. Updat. 2015, 21, 455-485. [CrossRef] [PubMed]

5. Dam, A.H.; Feenstra, I.; Westphal, J.R.; Ramos, L.; van Golde, R.J.; Kremer, J.A. Globozoospermia revisited. Hum. Reprod. Updat. 2007, 13, 63-75. [CrossRef] [PubMed]

6. Takeya, R.; Takeshige, K.; Sumimoto, H. Interaction of the PDZ domain of human PICK1 with class I ADP-ribosylation factors. Biochem. Biophys. Res. Commun. 2000, 267, 149-155. [CrossRef] [PubMed]

7. Staudinger, J.; Zhou, J.; Burgess, R.; Elledge, S.J.; Olson, E.N. PICK1: A perinuclear binding protein and substrate for protein kinase C isolated by the yeast two-hybrid system. J. Cell Biol. 1995, 128, $263-271$. [CrossRef] [PubMed]

8. Li, Y.H.; Zhang, N.; Wang, Y.N.; Shen, Y.; Wang, Y. Multiple faces of protein interacting with C kinase 1 (PICK1): Structure, function, and diseases. Neurochem. Int. 2016, 98, 115-121. [CrossRef] [PubMed]

9. Steinberg, J.P.; Takamiya, K.; Shen, Y.; Xia, J.; Rubio, M.E.; Yu, S.; Jin, W.; Thomas, G.M.; Linden, D.J.; Huganir, R.L. Targeted in vivo mutations of the AMPA receptor subunit GluR2 and its interacting protein PICK1 eliminate cerebellar long-term depression. Neuron 2006, 49, 845-860. [CrossRef] [PubMed]

10. Xiao, N.; Kam, C.; Shen, C.; Jin, W.; Wang, J.; Lee, K.M.; Jiang, L.; Xia, J. PICK1 deficiency causes male infertility in mice by disrupting acrosome formation. J. Clin. Investig. 2009, 119, 802-812. [CrossRef] [PubMed]

11. Harbuz, R.; Zouari, R.; Pierre, V.; Ben Khelifa, M.; Kharouf, M.; Coutton, C.; Merdassi, G.; Abada, F.; Escoffier, J.; Nikas, Y.; et al. A recurrent deletion of DPY19L2 causes infertility in man by blocking sperm head elongation and acrosome formation. Am. J. Hum. Genet. 2011, 88, 351-361. [CrossRef] [PubMed]

12. Pierre, V.; Martinez, G.; Coutton, C.; Delaroche, J.; Yassine, S.; Novella, C.; Pernet-Gallay, K.; Hennebicq, S.; Ray, P.F.; Arnoult, C. Absence of Dpy1912, a new inner nuclear membrane protein, causes globozoospermia in mice by preventing the anchoring of the acrosome to the nucleus. Development 2012, 139, 2955-2965. [CrossRef] [PubMed]

13. Koscinski, I.; Elinati, E.; Fossard, C.; Redin, C.; Muller, J.; Velez de la Calle, J.; Schmitt, F.; Ben Khelifa, M.; Ray, P.F.; Kilani, Z.; et al. DPY19L2 deletion as a major cause of globozoospermia. Am. J. Hum. Genet. 2011, 88, 344-350. [CrossRef] [PubMed]

14. Ounis, L.; Zoghmar, A.; Coutton, C.; Rouabah, L.; Hachemi, M.; Martinez, D.; Martinez, G.; Bellil, I.; Khelifi, D.; Arnoult, C.; et al. Mutations of the aurora kinase C gene causing macrozoospermia are the most frequent genetic cause of male infertility in Algerian men. Asian J. Androl. 2015, 17, 68-73. [PubMed]

15. Zhu, F.; Gong, F.; Lin, G.; Lu, G. DPY19L2 gene mutations are a major cause of globozoospermia: identification of three novel point mutations. Mol. Hum. Reprod. 2013, 19, 395-404. [CrossRef] [PubMed] 
16. Noveski, P.; Madjunkova, S.; Maleva, I.; Sotiroska, V.; Petanovski, Z.; Plaseska-Karanfilska, D. A Homozygous Deletion of the DPY1912 Gene is a Cause of Globozoospermia in Men from the Republic of Macedonia. Balk. J. Med. Genet. 2013, 16, 73-76. [CrossRef] [PubMed]

17. Coutton, C.; Zouari, R.; Abada, F.; Ben Khelifa, M.; Merdassi, G.; Triki, C.; Escalier, D.; Hesters, L.; Mitchell, V.; Levy, R.; et al. MLPA and sequence analysis of DPY19L2 reveals point mutations causing globozoospermia. Hum. Reprod. 2012, 27, 2549-2558. [CrossRef] [PubMed]

18. Xu, M.; Xiao, J.; Chen, J.; Li, J.; Yin, L.; Zhu, H.; Zhou, Z.; Sha, J. Identification and characterization of a novel human testis-specific Golgi protein, NYD-SP12. Mol. Hum. Reprod. 2003, 9, 9-17. [CrossRef] [PubMed]

19. Lu, L.; Lin, M.; Xu, M.; Zhou, Z.M.; Sha, J.H. Gene functional research using polyethylenimine-mediated in vivo gene transfection into mouse spermatogenic cells. Asian J. Androl. 2006, 8, 53-59. [CrossRef] [PubMed]

20. Wang, H.; Wan, H.; Li, X.; Liu, W.; Chen, Q.; Wang, Y.; Yang, L.; Tang, H.; Zhang, X.; Duan, E.; et al. Atg7 is required for acrosome biogenesis during spermatogenesis in mice. Cell Res. 2014, 24, 852-869. [CrossRef] [PubMed]

21. Xu, X.; Toselli, P.A.; Russell, L.D.; Seldin, D.C. Globozoospermia in mice lacking the casein kinase II alpha' catalytic subunit. Nat. Genet. 1999, 23, 118-121. [PubMed]

22. Yildiz, Y.; Matern, H.; Thompson, B.; Allegood, J.C.; Warren, R.L.; Ramirez, D.M.; Hammer, R.E.; Hamra, F.K.; Matern, S.; Russell, D.W. Mutation of beta-glucosidase 2 causes glycolipid storage disease and impaired male fertility. J. Clin. Investig. 2006, 116, 2985-2994. [CrossRef] [PubMed]

23. Han, F.; Liu, C.; Zhang, L.; Chen, M.; Zhou, Y.; Qin, Y.; Wang, Y.; Duo, S.; Cui, X.; Bao, S.; et al. Globozoospermia and lack of acrosome formation in GM130-deficient mice. Cell Death Dis. 2017, 8, e2532. [CrossRef] [PubMed]

24. Yao, R.; Ito, C.; Natsume, Y.; Sugitani, Y.; Yamanaka, H.; Kuretake, S.; Yanagida, K.; Sato, A.; Toshimori, K.; Noda, T. Lack of acrosome formation in mice lacking a Golgi protein, GOPC. Proc. Natl. Acad. Sci. USA 2002, 99, 11211-11216. [CrossRef] [PubMed]

25. Kang-Decker, N.; Mantchev, G.T.; Juneja, S.C.; McNiven, M.A.; van Deursen, J.M. Lack of acrosome formation in Hrb-deficient mice. Science 2001, 294, 1531-1533. [CrossRef] [PubMed]

26. Audouard, C.; Christians, E. Hsp90beta1 knockout targeted to male germline: A mouse model for globozoospermia. Fertil. Steril. 2011, 95, 1475-1477.e4. [CrossRef] [PubMed]

27. Doran, J.; Walters, C.; Kyle, V.; Wooding, P.; Hammett-Burke, R.; Colledge, W.H. Mfsd14a (Hiat1) gene disruption causes globozoospermia and infertility in male mice. Reproduction 2016, 152, 91-99. [CrossRef] [PubMed]

28. Liu, C.; Song, Z.; Wang, L.; Yu, H.; Liu, W.; Shang, Y.; Xu, Z.; Zhao, H.; Gao, F.; Wen, J.; et al. Sirt1 regulates acrosome biogenesis by modulating autophagic flux during spermiogenesis in mice. Development 2017, 144, 441-451. [CrossRef] [PubMed]

29. Oberheide, K.; Puchkov, D.; Jentsch, T.J. Loss of the Na+/H+ exchanger NHE8 causes male infertility in mice by disrupting acrosome formation. J. Biol. Chem. 2017, 292, 10845-10854. [CrossRef] [PubMed]

30. Funaki, T.; Kon, S.; Tanabe, K.; Natsume, W.; Sato, S.; Shimizu, T.; Yoshida, N.; Wong, W.F.; Ogura, A.; Ogawa, T.; et al. The Arf GAP SMAP2 is necessary for organized vesicle budding from the trans-Golgi network and subsequent acrosome formation in spermiogenesis. Mol. Biol. Cell 2013, 24, 2633-2644. [CrossRef] [PubMed]

31. Fujihara, Y.; Satouh, Y.; Inoue, N.; Isotani, A.; Ikawa, M.; Okabe, M. SPACA1-deficient male mice are infertile with abnormally shaped sperm heads reminiscent of globozoospermia. Development 2012, 139, 3583-3589. [CrossRef] [PubMed]

32. Lerer-Goldshtein, T.; Bel, S.; Shpungin, S.; Pery, E.; Motro, B.; Goldstein, R.S.; Bar-Sheshet, S.I.; Breitbart, H.; Nir, U. TMF/ARA160: A key regulator of sperm development. Dev. Biol. 2010, 348, 12-21. [CrossRef] [PubMed]

33. Paiardi, C.; Pasini, M.E.; Gioria, M.; Berruti, G. Failure of acrosome formation and globozoospermia in the wobbler mouse, a Vps54 spontaneous recessive mutant. Spermatogenesis 2011, 1, 52-62. [CrossRef] [PubMed]

34. Lin, Y.N.; Roy, A.; Yan, W.; Burns, K.H.; Matzuk, M.M. Loss of zona pellucida binding proteins in the acrosomal matrix disrupts acrosome biogenesis and sperm morphogenesis. Mol. Cell. Biol. 2007, 27, 6794-6805. [CrossRef] [PubMed] 
35. Yatsenko, A.N.; O'Neil, D.S.; Roy, A.; Arias-Mendoza, P.A.; Chen, R.; Murthy, L.J.; Lamb, D.J.; Matzuk, M.M. Association of mutations in the zona pellucida binding protein 1 (ZPBP1) gene with abnormal sperm head morphology in infertile men. Mol. Hum. Reprod. 2012, 18, 14-21. [CrossRef] [PubMed]

36. Cesario, M.M.; Bartles, J.R. Compartmentalization, processing and redistribution of the plasma membrane protein CE9 on rodent spermatozoa. Relationship of the annulus to domain boundaries in the plasma membrane of the tail. J. Cell Sci. 1994, 107 Pt 2, 561-570. [PubMed]

37. Miyata, H.; Castaneda, J.M.; Fujihara, Y.; Yu, Z.; Archambeault, D.R.; Isotani, A.; Kiyozumi, D.; Kriseman, M.L.; Mashiko, D.; Matsumura, T.; et al. Genome engineering uncovers 54 evolutionarily conserved and testis-enriched genes that are not required for male fertility in mice. Proc. Natl. Acad. Sci. USA 2016, 113, 7704-7710. [CrossRef] [PubMed]

38. Oji, A.; Noda, T.; Fujihara, Y.; Miyata, H.; Kim, Y.J.; Muto, M.; Nozawa, K.; Matsumura, T.; Isotani, A.; Ikawa, M. CRISPR/Cas9 mediated genome editing in ES cells and its application for chimeric analysis in mice. Sci. Rep. 2016, 6, 31666. [CrossRef] [PubMed]

39. Fujihara, Y.; Kaseda, K.; Inoue, N.; Ikawa, M.; Okabe, M. Production of mouse pups from germline transmission-failed knockout chimeras. Transgenic Res. 2013, 22, 195-200. [CrossRef] [PubMed]

40. Naito, Y.; Hino, K.; Bono, H.; Ui-Tei, K. CRISPRdirect: Software for designing CRISPR/Cas guide RNA with reduced off-target sites. Bioinformatics 2015, 31, 1120-1123. [CrossRef] [PubMed]

41. Fujihara, Y.; Tokuhiro, K.; Muro, Y.; Kondoh, G.; Araki, Y.; Ikawa, M.; Okabe, M. Expression of TEX101, regulated by ACE, is essential for the production of fertile mouse spermatozoa. Proc. Natl. Acad. Sci. USA 2013, 110, 8111-8116. [CrossRef] [PubMed]

42. Yamaguchi, R.; Yamagata, K.; Hasuwa, H.; Inano, E.; Ikawa, M.; Okabe, M. Cd52, known as a major maturation-associated sperm membrane antigen secreted from the epididymis, is not required for fertilization in the mouse. Genes Cells 2008, 13, 851-861. [CrossRef] [PubMed]

43. Muto, M.; Fujihara, Y.; Tobita, T.; Kiyozumi, D.; Ikawa, M. Lentiviral Vector-mediated complementation restored fetal viability but not placental hyperplasia in Plac1-deficient mice. Biol. Reprod. 2016, 94, 6. [CrossRef] [PubMed]

44. Yamaguchi, R.; Yamagata, K.; Ikawa, M.; Moss, S.B.; Okabe, M. Aberrant distribution of ADAM3 in sperm from both angiotensin-converting enzyme (Ace)- and calmegin (Clgn)-deficient mice. Biol. Reprod. 2006, 75, 760-766. [CrossRef] [PubMed] 